\title{
Children with diabetes friendly services: A blueprint
}

Sir,

Psychosocial factors are important modulators for the success of treatment. ${ }^{[1]}$ Identification of key obstacle and tackling with the same improves long-term prognosis of diabetes. It is important to include psychological assessment and treatment into routine care rather than wait for the identification of a specific problem or deterioration in psychological status. ${ }^{[1]}$ The International Society for Pediatric and Adolescent Diabetes guidelines state that "Psychosocial factors are the most important influences affecting the care and management of diabetes." ${ }^{2]}$ The recently published article, "Children with diabetes friendly services: A blueprint" brought out this important aspect into the limelight. ${ }^{[3]}$ Beyond the biological competency of the treating physician, acquiring the skills on dealing with the psychosocial concerns of the patient has also become the basic need of care. The literature review reveals that 
people who do not have diabetes mellitus do not perceive it to be a stigmatized condition. In contrast, people who have diabetes report the feeling of being judged and constantly monitored. The diabetes related stigma may have negative consequences on psychological well-being as well on clinical outcomes. ${ }^{[4]}$

The second Diabetes Attitudes, Wishes, and Needs (DAWN2) study aimed to assess psychosocial outcomes in people with diabetes across 17 countries has recently been published. ${ }^{[5]}$ Diabetes-related distress Problem Areas in Diabetes Scale 5 score $\geq 40$ was reported by $44.6 \%$ of participants. Overall quality of life was rated either "poor" or "very poor" by $12.2 \%$ of participants. Diabetes had a negative impact on all aspects investigated, ranging from $20.5 \%$ to $62.2 \%$ on relationship with family/ friends and physical health, respectively. The availability of person-centered chronic illness care and support for active involvement was rated as low. Only $48.8 \%$ of respondents had participated in diabetes educational programs/activities to help manage their diabetes.

Here, it is also important to mention regarding DAWN Youth study. ${ }^{[6]}$ The DAWN Youth surveys generated new knowledge and insights of the unique challenges of childhood diabetes amongst governments, health organizations, professionals, families, and policy makers.

Five DAWN Youth goals were identified to address the insights:

- Improve access to age appropriate care, education, and psychosocial support

- Improve support from schools

- Improve peer support

- Improve educational and psychosocial support for parents and families

- Address childhood obesity and type 2 diabetes.

The DAWN Youth program aims to facilitate action and advocacy to improve the lives of young people with diabetes and their families with special focus on overcoming psychosocial barriers and the DAWN Youth Call to Action.

We feel that there should be an increased stress upon imparting diabetes education in cultural/age/sex specific manner. Involvement of psychologists with special interest in diabetes can be a great asset. Appropriate social concerns need to be addressed, whether it may need involvement of community workers and may require some support from government agencies/non-governmental organizations in terms of finance/free education and other resources needed for well-being of children with diabetes.
The great value of change in social environment cannot be overemphasized, especially in Indian family system. In India, entire family is actively involved in care of these patients. It is also remarkable to note that this care can extend for very prolonged period of time. Though, it is beneficial in one aspect that child with diabetes has always some support at hand and it increases compliance to some extent, but, other side of this situation is undue expectations and judgmental behavior of family. Moreover, as in other chronic diseases, caregiver burnout is frequently seen in these families. To avoid all these social issues, it is paramount that family is adequately counseled. Similar situations are encountered by these children in schools too. All stakeholders in this process should be made aware that with modern advances in treatment, these children can live an absolutely normal life with only little extra care and caution.

In the social environment, peer-interaction may be encouraged among children with diabetes. They should be encouraged to share their problems with other children of the same age or elder to them. The experiences of handling the situations by one may be an inspiration for the others. They should also be encouraged to become role models, as they are more familiar with the problems, the "diabetics" face in day-to-day life. They can play an important role to deal with newly diagnosed cases of diabetes in future and may place them at a better level to cope up with the stress associated with diabetes.

In short, the child with diabetes should be holistically taken care by covering all domains of health, be it biological, psychological, or social aspects. All efforts should be made to mark their journey as a role model in diabetes care.

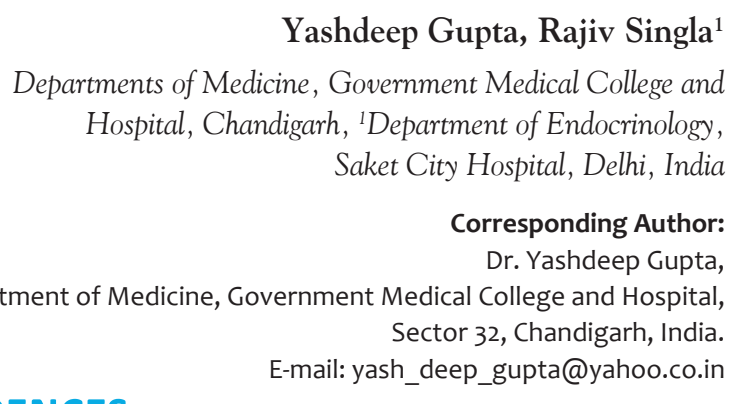

\section{REFERENCES}

1. Sridhar GR. Dealing with depression in metabolic disorders. Depression in medically-ill patients. In: Desai NG, editor. ECAB Clinical Update: Psychiatry. New Delhi: Elsevier; 2012. p. 20-36.

2. ISPAD. Consensus guidelines for the management of type 1 diabetes mellitus in children and adolescents, 2000. Available from: http://www.diabetesguidelines.com/health/dkw/pro/ guidelines/ispad/ispad/asp. [Last accessed on 2013 Jul 31].

3. Kalra S, John M, Unnikrishnan AG, Sahay R, Baruah MP, Bantwal G. Children with diabetes friendly services: A blueprint. J Soc Health Diabetes 2013;1:75-8. 
4. Schabert J, Browne JL, Mosely K, Speight J. Social stigma in diabetes: A framework to understand a growing problem for an increasing epidemic. Patient 2013;6:1-10.

5. Nicolucci A, Kovacs Burns K, Holt RI, Comaschi M, Hermanns N, Ishii $\mathrm{H}$, et al. Diabetes Attitudes, Wishes and Needs second study $\left(\mathrm{DAWN2}{ }^{\mathrm{TM}}\right.$ ): Cross-national benchmarking of diabetes-related psychosocial outcomes for people with diabetes. Diabet Med 2013;30:778-88.

6. DAWN Youth study. Available from: http://www.dawnstudy. com/dawnprogramme/dawnyouth.asp. [Last accessed on 2013 Jul 31].

\begin{tabular}{|l|l|}
\hline \multicolumn{2}{|c|}{ Access this article online } \\
\hline Quick Response Code: & Website: \\
\hline & www.josh.net \\
\hline & \\
\hline & \\
\hline
\end{tabular}

